Original Research Paper

\title{
Optimization of Chelating Process of Polysaccharides of Lyophyllum decastes with Zinc and Its Antioxidant Activity
}

\author{
Bing Xu, Yi Dai, Jing Hong and Yiyong Chen* \\ School of Biology and Food Engineering, Changshu Institute of Technology, Changshu 215500, China
}

\author{
Article history \\ Received: 09-02-2020 \\ Revised: 03-08-2020 \\ Accepted: 25-08-2020 \\ Corresponding Author: \\ Yiyong Chen \\ School of Biology and Food \\ Engineering, Changshu \\ Institute of Technology, \\ Changshu 215500, China \\ Email: 103158770@qq.com
}

\begin{abstract}
In this study, polysaccharides of Lyophyllum decastes (LDS) were used as raw material. The chelating rate was set as the index, the effect of chelating time, mass ratio and initial mass concentration on chelating rate was investigated. Response surface method was used to optimize the preparation technology of LDS and Zinc (II) chelate (LDS-Zn) based on single factor experiments. LDS-Zn was analyzed by FTIR. Antioxidant activity in vitro of LDS and LDS-Zn was investigated. Research results showed that optimal preparation conditions of LDS-Zn were as follows: Chelating time was $4 \mathrm{~h}$, mass ratio (LDS with zinc) was 6:1, initial mass concentration (zinc) was $4 \mathrm{mg} / \mathrm{mL}$. LDS achieved the best chelating rate as high as $87.08 \%$. Infrared spectroscopy analysis showed that Zinc (II) successfully chelated with LDS. Compared with LDS, LDS$\mathrm{Zn}$ had better scavenging effect on DPPH free radicals and hydroxyl radicals with an increase of antioxidant activity by 23.46 and $16.77 \%$, respectively. These results indicated that LDS-Zn can be expected to serve as a nutritional $\mathrm{Zn}$ supplement with antioxidant activity.
\end{abstract}

Keywords: Lyophyllum decastes, Polysaccharide, Single Factor, Chelation, Response Surface, Antioxidant

\section{Introduction}

Lyophyllum decastes is a delicious food with medicinal properties (Cheng, 2014). Its fruit body is rich in anticancer polysaccharides and has adjuvant treatment effects on six major diseases, such as diabetes and hypertension. It is a low-calorie, low-fat health care product that has the unique effects of preventing constipation, nourishing beauty, preventing and fighting cancer, improving immunity, increasing intelligence and prolonging life (Shang, 2014). In recent years, polysaccharide $\mathrm{Zn}$-chelate has become a research hotspot as an organic $\mathrm{Zn}$ supplement. Some synthetic polysaccharide $\mathrm{Zn}$-chelate included Flammulina velutipe polysaccharide- $\mathrm{Zn}^{2+}$ chelate (Zhao et al., 2016; He and $\mathrm{Lu}, 2011)$, Pleurotus eryngii polysaccharide- $\mathrm{Zn}^{2+}$ chelate (Gu et al., 2019), black fungus polysaccharide $\mathrm{Zn}$ complex (Li and Wang, 2006), d-glucosamine $\mathrm{Zn}$ complex (Raikwar et al., 2019) and chitosan $\mathrm{Zn}$ complexes (Ding et al., 2003). These synthetic polysaccharide $\mathrm{Zn}$ complexes can be developed into a new $\mathrm{Zn}$ supplement (Debon and Tester, 2001; Hedemann et al., 2006; Namkung et al., 2006). However, few studies on the chelation and bioactivity of polysaccharides of
Lyophyllum decastes (LDS) and trace elements have been conducted.

In this study, polysaccharide (LDS) was selected as raw material. The chelation of polysaccharides (LDS) and $\mathrm{Zn}$ (II) were studied. Furthermore, the effect of chelation time, mass ratio and initial $\mathrm{Zn}$ (II) concentration on the chelation of polysaccharide (LDS) and $\mathrm{Zn}(\mathrm{II})$ were studied. Optimal chelation parameters were determined by response surface experiment. The chelated product was analyzed by Fourier transform infrared spectroscopy. So far, some polysaccharide zinc complexes such as Dictyophora indusiata polysaccharide-zinc complex with antiproliferative activity (Liao et al., 2015) and Prunella vulgaris polysaccharide-zinc complex with antiproliferative activity (Li et al., 2016) have been successfully prepared. Fructus Mori polysaccharide and zinc complex(MFP4P-Zn) had higher antioxidant and hypoglycemic activities than MFP4P at the same concentration (Wang et al., 2019). The integration of Fritillaria ussuriensis polysaccharide and $\mathrm{Zn}$ greatly enhanced the antioxidant activities due to the synergistic effect, which provided vital theoretical basis for the promising antioxidant and zinc supplement 
(Zhang et al., 2020). In the present study, optimization of chelating process of LDS with Zinc (LDS-Zn) and its antioxidant activity were investigated. LDS-Zn could be used as an emerging $\mathrm{Zn}$ supplement with antioxidant activity in the future. Therefore, the study can provide a theoretical basis including preparation and antioxidant activity for the development of a novel natural zinc supplement (LDS-Zn).

\section{Materials and Methods}

\section{Material and Reagent}

LDS was purchased from Fujian Gutian Rongxiang Biological Technology Co., Ltd.; DPPH (1,1-diphenyl-2brothquinone) was purchased from Kuer Chemical Technology (Beijing) Co., Ltd.; Tris (tris hydroxy methyl aminomethane) was purchased from Wuhan Benjamin Pharmaceutical Co., Ltd.; $\mathrm{CH}_{3} \mathrm{CH}_{2} \mathrm{CH}_{2} \mathrm{CH}_{2} \mathrm{OH}$, $\mathrm{CH}_{3} \mathrm{CH}_{2} \mathrm{OH}, \mathrm{NaOH}, \mathrm{H}_{2} \mathrm{O}_{2}, \mathrm{FeSO}_{4} \cdot 7 \mathrm{H}_{2} \mathrm{O}, \mathrm{HCl}, \mathrm{H}_{2} \mathrm{SO}_{4}$, $\mathrm{C}_{7} \mathrm{H}_{6} \mathrm{O}_{3}, \mathrm{ZnSO}_{4} \cdot 7 \mathrm{H}_{2} \mathrm{O}, \mathrm{ZnCl}_{2}$ and $\mathrm{Zn}\left(\mathrm{CH}_{2} \mathrm{COO}\right)_{2} \cdot 2 \mathrm{H}_{2} \mathrm{O}$ are all of analytical purity.

\section{Instruments and Equipment}

$722 \mathrm{~N}$ visible spectrophotometer was from Beijing Kangfulai Technology Co., Ltd.; Fourier infrared spectrometer was from Tianjin Gangdong Technology Development Co., Ltd.; SP-3520 Atomic Absorption Spectrophotometer was from Shanghai Zhongyong Testing Equipment Co., Ltd.; HH-6 water bath was from Changzhou Kaihang Instrument Co., Ltd.; N-1300D-W Rotary Evaporator was from Shanghai Zhucheng Industrial Co., Ltd.; CAV264 electronic precision balance was from Shenzhen Huaiyi Electronic Technology Co., Ltd.; UV-6300 UV-visible spectrophotometer was from Shandong Chentuo Scientific Instrument Co., Ltd.; NHWY-111B constant temperature shaker was from Shenzhen Yixin Instrument Equipment Co., Ltd.; TD5A-WS centrifuge was from Xiangyi Centrifuge Instrument Co., Ltd.; XY-10 crusher was from Hebei Baoer Technology Development Co., Ltd.; DF-101S constant temperature heating magnetic stirrer was from Shanghai Tin, Scientific Instrument Co., Ltd.; $\mathrm{pH}$ meter was from Shandong Detian Environmental Protection Equipment Co., Ltd.

\section{Methods}

Preparation of Chelate of Polysaccharide and Zinc (LDS-Zn)

LDS powder was dissolved with water, stirred and adjusted for $\mathrm{pH}$. Zn sulfate was added according to the preferred ratio, stirred and controlled for temperature for chelation. The solution was filtered, concentrated and then precipitated (Yang et al., 2004; Hu et al., 2007; Wang,
2008; Jung and Kim, 2007). The solution was freeze-dried under vacuum environment to obtain LDS-Zn.

\section{Calculation of Chelating Rate}

The chelating rate was calculated according to the following equation (Yang et al., 2017a):

$$
\text { Chelating rate }(\%)=\left(C_{0}-C\right) / C_{0} \times 100
$$

where, $C_{0}$ is the mass concentration $(\mathrm{g} / \mathrm{L})$ of $\mathrm{Zn}(\mathrm{II})$ in the solution before chelation. $C$ is the mass concentration $(\mathrm{g} / \mathrm{L})$ of $\mathrm{Zn}(\mathrm{II})$ in the solution after chelation.

\section{Single-Factor Experiment}

\section{Effect of Chelating Time on Chelating Rate}

$0.4 \mathrm{~g}$ of $\mathrm{ZnSO}_{4} \cdot 7 \mathrm{H}_{2} \mathrm{O}$ was dissolved in $100 \mathrm{~mL}$ of distilled water to prepare a solution with a mass concentration of $4 \mathrm{mg} / \mathrm{mL}$. LDS and $\mathrm{Zn}$ (II) solution were added with a mass ratio of $4: 1$. Chelation was performed under neutral $\mathrm{pH}, 30^{\circ} \mathrm{C}$ at a speed of 150 $\mathrm{r} / \mathrm{min}$. The specimens were collected at 1, 2, 4, 6 and 8 h, respectively. After alcohol precipitation, the supernatant was obtained. The $\mathrm{Zn}$ concentration of these specimens was determined and the chelating rate was calculated (Qin et al., 2009). The best chelating time was determined.

\section{Effect of Mass Ratio on Chelating Rate}

$0.4 \mathrm{~g}$ of $\mathrm{ZnSO}_{4} \cdot 7 \mathrm{H}_{2} \mathrm{O}$ was dissolved in $100 \mathrm{~mL}$ of distilled water to prepare a solution with a $\mathrm{Zn}$ concentration of $4 \mathrm{mg} / \mathrm{mL}$. LDS and $\mathrm{Zn}$ (II) solution were added with a mass ratio of $1: 1,2: 1,3: 1,4: 1,5: 1$ and $6: 1$, respectively. Chelation was performed under neutral $\mathrm{pH}, 30^{\circ} \mathrm{C}$ at a speed a speed of $150 \mathrm{r} / \mathrm{min}$ for 4 h. After alcohol precipitation, the supernatant was obtained. The $\mathrm{Zn}$ concentration of these specimens was determined and the chelating rate was calculated. The best mass ratio was determined.

\section{Effect of Initial Mass Concentration on Chelating Rate}

$0.1,0.2,0.3,0.4,0.5$ and $0.6 \mathrm{~g}$ of $\mathrm{ZnSO}_{4} \cdot 7 \mathrm{H}_{2} \mathrm{O}$ were added to $100 \mathrm{~mL}$ of distilled water to prepare a solution of $\mathrm{Zn}$ (II) with an initial concentration of 1,2 , 3, 4, 5 and $6 \mathrm{mg} / \mathrm{mL}$, respectively. LDS and $\mathrm{Zn}(\mathrm{II})$ were added to the solution with a mass ratio of $5: 1$. Chelation was performed under neutral $\mathrm{pH}, 30^{\circ} \mathrm{C}$ at a speed of $150 \mathrm{r} / \mathrm{min}$ for $4 \mathrm{~h}$. After alcohol precipitation, the supernatant was obtained. The $\mathrm{Zn}$ concentration of these specimens was determined and the chelating rate was calculated. The best initial mass concentration was determined. 


\section{Response Surface Test}

The BBD center combination test design principle was used in this experiment (Yang et al., 2017b; $\mathrm{Wu}$ et al., 2014). Based on the results of all singlefactor experiments, chelation time, mass ratio and initial mass concentrations were selected as independent variables. The response surface test was performed with the chelation rate of the chelate as the response value. The experiment was carried out under three factors and three levels.

A total of 15 trials were conducted including 12 factorial points and 3 zero points. Test error was estimated by repeating the test at the center point as shown in Table 1. The optimal process conditions for preparation technology of LDS-Zn were optimized by regression analysis of the test results. When $\mathrm{p}<0.05$, the significance of all terms in the polynomial was considered statistically different.

\section{Structural Characterization of LDS and LDS-Zn}

Dry potassium bromide solid was added to an appropriate amount of sample. They were fully grounded in an agate mortar under the illumination of an infrared lamp. The sample was compressed into a transparent sheet. The infrared spectrum was measured in the wavenumber range of $400-4000 \mathrm{~cm}^{-1}$ by an infrared spectrometer.

\section{Determination of Antioxidant Activity}

\section{Determination of DPPH Free Radical Scavenging Capacity}

$0.004 \mathrm{~g}$ of DPPH was dissolved in $100 \%$ ethanol to a constant volume of $1 \mathrm{~L}$. $0.1 \mathrm{mmol} / \mathrm{L} \mathrm{DPPH}$ solution was prepared and stored away from light. Different concentrations of LDS and LDS-Zn with $2.0 \mathrm{~mL}$ each were obtained, placed in different tubes and added with $2.0 \mathrm{~mL}$ of DPPH solution. The tubes were then stirred to homogenize the solution. Their reaction lasted 30 min under an environment without sunlight. Absorbance value was measured at $517 \mathrm{~nm}$. The blank control group was replaced with distilled water. The recorded value was set as A1. DPPH free radical scavenging rate was calculated as follows and the measurement was repeated three times (Chen and Zhang, 2016):

$$
\text { Clearance rate } / \%=[1-(A 2-A 1) / A 0] \times 100
$$

where $A 2$ represents the absorbance measured by different concentrations of polysaccharide (LDS). A1 represents the absorbance measured by using distilled water instead of DPPH and $A 0$ represents the absorbance measured by replacing distilled polysaccharide (LDS) with distilled water.
Table 1: Level of response surface factors

\begin{tabular}{lll}
\hline $\begin{array}{l}\text { Anitial mass } \\
\text { concentration }(\mathrm{mg} / \mathrm{mL})\end{array}$ & $\begin{array}{l}\text { B } \\
\text { Chelating } \\
\text { time }(\mathrm{h})\end{array}$ & $\begin{array}{l}\mathrm{C} \\
\text { Mass ratio } \\
(\mathrm{mg} / \mathrm{mg})\end{array}$ \\
\hline 3 & 2 & $5: 1$ \\
4 & 4 & $6: 1$ \\
5 & 6 & $7: 1$ \\
\hline
\end{tabular}

Determination of Hydroxyl Radical Scavenging Ability

$0.3 \mathrm{~mL}$ salicylic acid solution $(20 \mathrm{mmol} / \mathrm{L}), 1.0 \mathrm{~mL}$ of $\mathrm{FeSO}_{4} \cdot 7 \mathrm{H}_{2} \mathrm{O}$ solution $(1.5 \mathrm{mmol} / \mathrm{L}), 2.0 \mathrm{~mL}$ different concentrations of LDS and LDS-Zn solution and $0.7 \mathrm{~mL}$ $\mathrm{H}_{2} \mathrm{O}_{2}(6 \mathrm{mmol} / \mathrm{L})$ were added together to form a $3 \mathrm{ml}$ reaction solution. The solution was then stirred to homogenize it and placed in a constant temperature water bath at $37^{\circ} \mathrm{C}$ for $60 \mathrm{~min}$. Absorbance was measured at 517 $\mathrm{nm}$. The blank control group was replaced with distilled water. The measurement was repeated three times and the average value was obtained. The formula was performed as follows to calculate the clearance rate. The measurement was repeated three times:

$$
\text { Clearance rate } / \%=[1-(A 2-A 1) / A 3] \times 100
$$

where $A 1$ is the absorbance measured by replacing distilled water with salicylic acid. $A 2$ is the absorbance measured for different concentrations of polysaccharide. $A 3$ is the absorbance measured by replacing different concentrations of polysaccharide with distilled water.

\section{Results and Discussion}

\section{Preparation Process of LDS-Zn}

\section{Single Factor Experiment \\ Effect of Chelating Time on Chelating Rate}

As can be seen from Fig. 1, the chelating rate increased with the chelating time and the chelating reaction became more sufficient (Dong et al., 2016). With the increase of time, the chelation of LDS with $\mathrm{Zn}$ (II) was more sufficient. The chelating rate increased with time. The chelating rate was the highest when the time was $4 \mathrm{~h}$. After $4 \mathrm{~h}$, too long time caused the instability of LDS structure, resulting in a decrease in chelation rate. Therefore, the optimal chelating time was $4 \mathrm{~h}$.

\section{Effect of Mass Ratio on Chelating Rate}

As shown in Fig. 2, when the mass ratio of LDS and $\mathrm{Zn}$ (II) was 6:1, the chelating rate was the highest. If the mass ratio severely dropped, the ring structure of LDS was not sufficiently stable. Thus, the chelating rate became small. The increase in the mass ratio adversely 
affected the progress of the chelating reaction and thus decreased the chelating rate. Therefore, the optimal mass ratio was 6:1.

\section{Effect of Initial Mass Concentration on Chelating Rate}

Figure 3 showed that the chelating rate increased when the concentration of $\mathrm{Zn}(\mathrm{II})$ increased. However, the excessive concentration of $\mathrm{Zn}(\mathrm{II})$ adversely affected the progress of the chelating reaction, resulting in a decrease in the chelating rate. At a concentration of $4 \mathrm{mg} / \mathrm{mL}$, chelating rate was the highest. However, when the concentration of $\mathrm{Zn}(\mathrm{II})$ increased further, the chelation rate decreased. Therefore, the optimum initial mass concentration of $\mathrm{Zn}(\mathrm{II})$ was $4 \mathrm{mg} / \mathrm{mL}$.

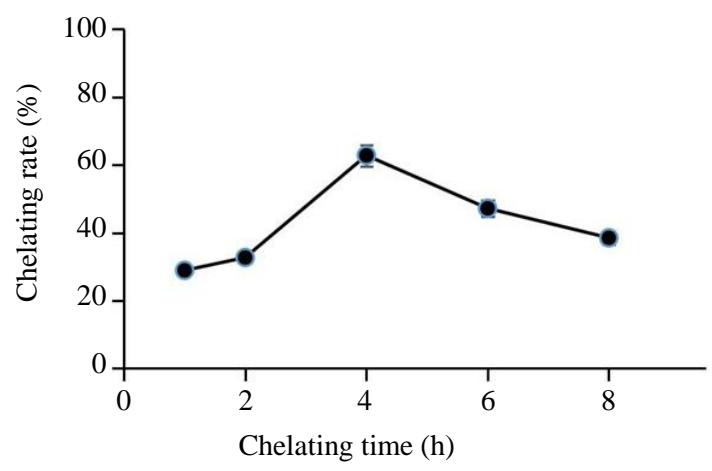

Fig. 1: Effect of chelating time on chelating rate

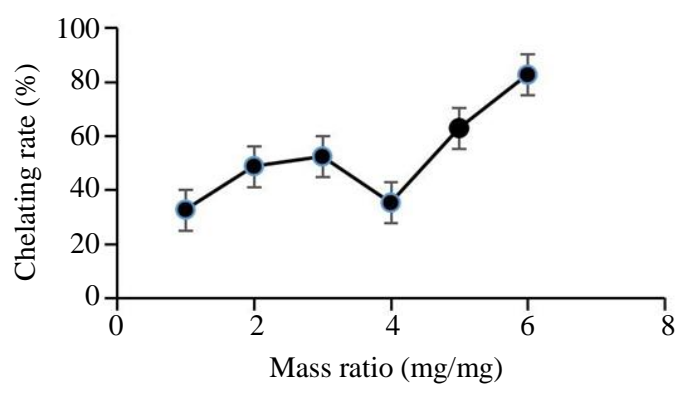

Fig. 2: Effect of mass ratio on chelating rate

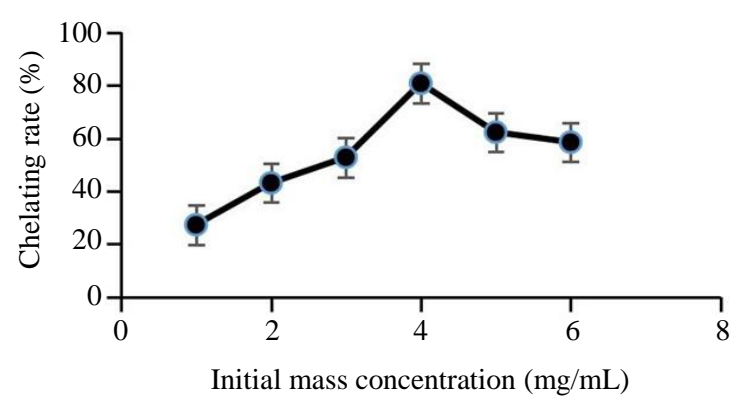

Fig. 3: Effect of initial mass concentration on chelating rate

\section{Optimization of LDS-Zn Preparation Process Conditions}

\section{Establishment and Analysis of Response Models}

The results of the single-factor test were entered into the Design-Expert software and the response surface experimental design and data were obtained (Table 2). The test results of the table design test, the regression coefficient of the test model (Table 3) and the response surface map (Fig. 4 to 6) were listed.

Using the chelating rate of LDS-Zn(II) as response value, the response surface analysis was performed by using Design-Expert 8.0 software (Table 2). A quadratic multiple regression equation was obtained for initial mass concentrations (A), chelating time (B) and mass ratio(C):

$$
\begin{aligned}
& Y=+81.63926-0.1286 * A+0.05537 * B+0.17202 \\
& * C-8.21595 E-00 * B * C+1.16287-003 * \\
& A^{2}-9.87456-004 * C^{2}
\end{aligned}
$$

As shown in Table 3, the quadratic polynomial model indicated that the effect was extremely significant $(p<0.01)$. The missing term $(p>0.05)$ indicated that the effect was not significant. The effect of $\mathrm{A}^{2}$ was extremely significant for chelating rate $(\mathrm{p}<0.01)$. The effect of $\mathrm{B}^{2}$ was significant for chelating rate $(p<0.05)$. Similarly, the effect of $\mathrm{C}^{2}$ was not significant for chelating rate ( $p>0.05$ ). The $p$ value of the misfit term of the equation was 0.2939 , indicating that the influence was not significant and the model was accurate.

\section{Response Surface Analysis}

The response surface contour line represented the interaction between the factors. The steep surface indicated that the factor greatly influenced the chelation rate. The gentleness could be judged that the effect was not significant. The shape and intensity of the contours could also reflect the extent to which factors affect the chelation rate. The oval shape indicated that the effect was significant and the circle was not significant. Figure 4 indicated that the initial mass and chelation time greatly influenced the chelation rate. Figure 5 indicated that the contour was elliptical and the pattern was steep, indicating that the initial mass concentration and mass ratio greatly influenced the chelation rate. Figure 6 indicated that the contour line was dense and the graph was steep, indicating that the mass ratio and the chelation time greatly influenced the chelation rate.

\section{Optimal Process Conditions Determination and Verification Test}

The response surface test results were analyzed using the Design-Expert software. Based on the response 
surface plots, contour plots and analysis of variance, effect of chelation time, initial mass concentration and mass ratio on chelating rate was optimized and analyzed. The optimal preparation conditions of LDS-Zn were as follows: Chelating time was $4 \mathrm{~h}$, mass ratio (LDS with zinc) was 6:1, initial mass concentration (zinc) was 4 $\mathrm{mg} / \mathrm{mL}$. LDS achieved the best chelating rate as high as $87.08 \%$. To verify the adequacy of the model equation, three verification experiments were performed under optimal conditions as described above. Chelating rate was $85.04,86.42$ and $85.65 \%$ in three parallel experiments. An average chelating rate was $85.70 \%$, which was close to predicted value. The result indicated that the chelating process condition parameters obtained by the response surface method could be used. Therefore, it was achievable to predict the model based on the response surface method.
Table 2: Response surface experimental design and data

\begin{tabular}{lrrrl}
\hline Test number & A & B & C & Chelating rate (\%) \\
\hline 1 & -1 & 1 & 0 & 84.67 \\
2 & 0 & 0 & 0 & 87.08 \\
3 & -1 & -1 & 0 & 84.08 \\
4 & 0 & 1 & -1 & 86.82 \\
5 & 0 & 0 & 0 & 87.09 \\
6 & 1 & 0 & -1 & 85.31 \\
7 & 1 & 0 & 1 & 85.63 \\
8 & 0 & -1 & 0 & 85.03 \\
9 & 0 & 0 & -1 & 85.03 \\
10 & 0 & 1 & 1 & 85.93 \\
11 & -1 & 0 & 1 & 83.43 \\
12 & -1 & 0 & 0 & 85.67 \\
13 & 0 & -1 & 1 & 84.61 \\
14 & 0 & 1 & 0 & 86.55 \\
15 & 0 & 0 & -1 & 84.62 \\
16 & 0 & 0 & 1 & 85.43 \\
17 & 0 & 0 & 0 & 87.27
\end{tabular}

Table 3: Variance analysis of regression models

\begin{tabular}{lcclll}
\hline Source & Sum of squares & Degrees of freedom & Mean square & F value & P value \\
\hline Model & 26.150 & 9 & 2.910 & 2.590 & 0.0002 \\
$\mathrm{~A}$ & 1.070 & 1 & 1.070 & 0.960 & 0.0004 \\
$\mathrm{~B}$ & 0.670 & 1 & 0.670 & 2.910 & 0.0009 \\
$\mathrm{C}$ & 3.260 & 1 & 3.260 & 0.720 & 0.0001 \\
$\mathrm{AB}$ & 0.810 & 1 & 0.810 & 0.037 & 0.4237 \\
$\mathrm{AC}$ & 0.042 & 1 & 0.042 & 2.170 & 0.8521 \\
$\mathrm{BC}$ & 2.430 & 1 & 2.430 & 2.260 & 0.1844 \\
$\mathrm{~A}^{2}$ & 2.530 & 1 & 2.530 & 6.570 & 0.0019 \\
$\mathrm{~B}^{2}$ & 7.370 & 1 & 7.370 & 5.500 & 0.0374 \\
$\mathrm{C}^{2}$ & 6.170 & 1 & 6.170 & 1.700 & 0.0515 \\
Residual error & 7.860 & 7 & 1.120 & & \\
Lack of fit & 4.470 & 3 & 0.850 & & 0.2939 \\
Pure error & 3.390 & 4 & & &
\end{tabular}

(Note: $\mathrm{p}<0.05$ means the difference is significant; $\mathrm{p}<0.01$ means the difference is extremely significant; $\mathrm{p}>0.05$ means the difference is not significant.)

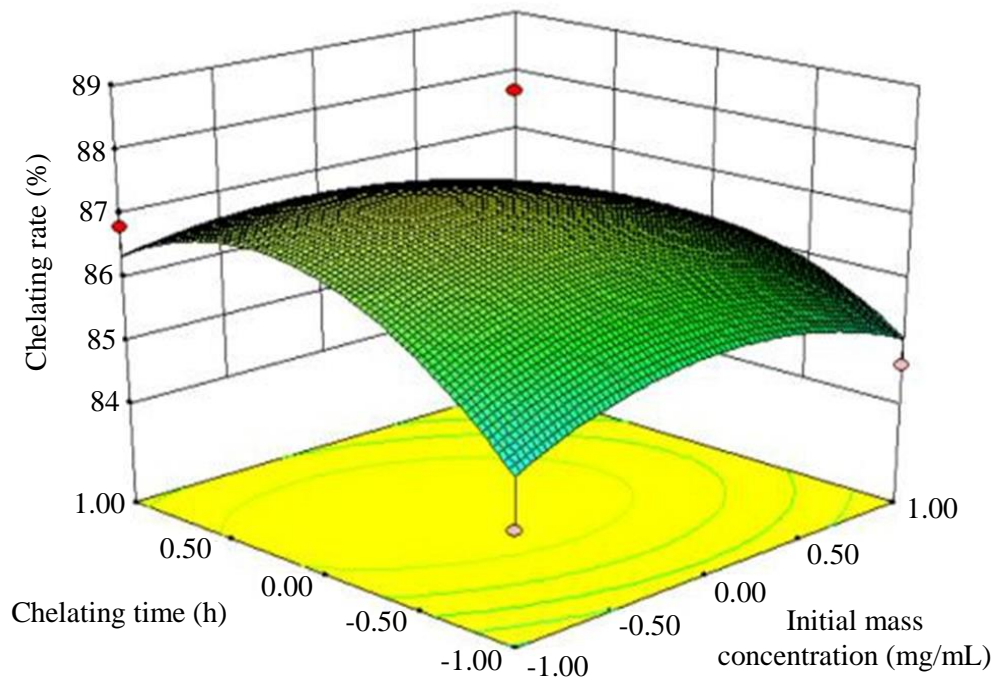

Fig. 4: Interaction of initial mass concentration and chelating time 


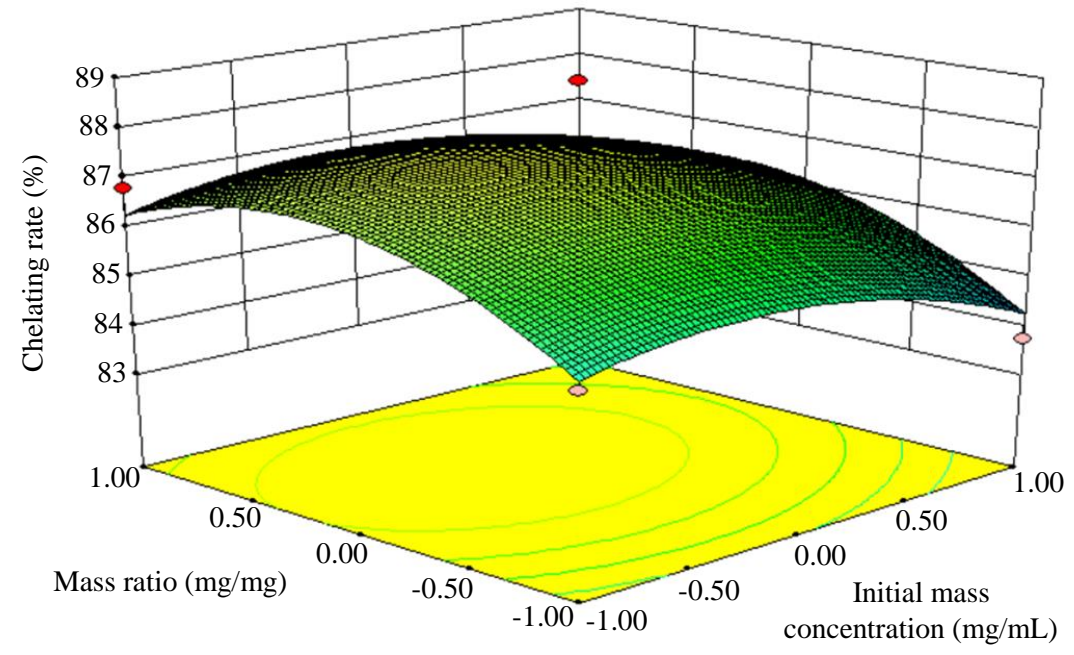

Fig. 5: Interaction of initial mass concentration and mass ratio

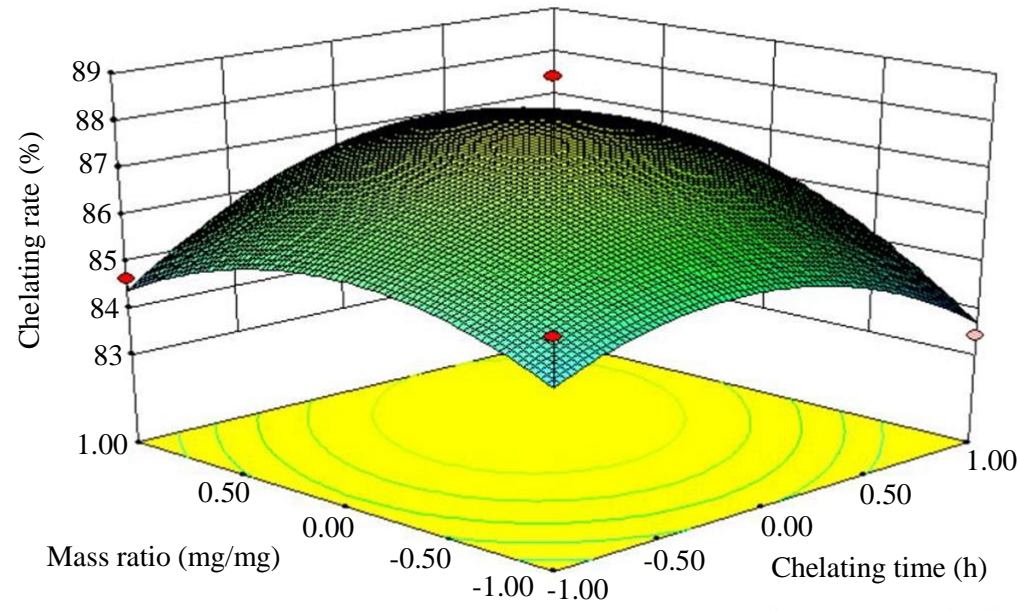

Fig. 6: Interaction of mass ratio and chelation time

\section{Infrared Spectroscopy Analysis of LDS and LDS-Zn}

A comparison of the infrared spectra of LDS and LDS-Zn (Fig. 7) showed that LDS had a typical polysaccharide characteristic absorption peak. If the $\mathrm{Zn}$ substance was complexed with polysaccharide (LDS), the stretching vibration absorption peak $\left(1600 \mathrm{~cm}^{-1}\right)$ of the hydroxyl group $(-\mathrm{OH})$ in the polysaccharide molecule and its variable angle vibration $\left(1384 \mathrm{~cm}^{-1}\right)$ might shift towards the red direction. Given the influence of moisture in the $\mathrm{KBr}$ tablet, the change of the hydroxyl absorption peak of the hydroxy group was used as the basis to investigate the chelation of the sample polysaccharide. The direction of the LDS-Zn wave shifted and the stretching vibration peak of $-\mathrm{OH}$ was at $3300 \mathrm{~cm}^{-1}$. The absorption intensity was weak. Its variable angle vibration was weaker than that of unchelated form. The $\mathrm{C}=\mathrm{O}$ vibration absorption peak was at $2900 \mathrm{~cm}^{-1}$ and the absorption intensity was lowered. This red shift phenomenon and change in the absorption intensity of the group indicated that the $\mathrm{Zn}$ ion was chelated with the -OH of LDS (Cui et al., 2018).

\section{Antioxidant Activity of LDS and LDS-Zn}

\section{Scavenging Effect of LDS and LDS-Zn on DPPH Free Radicals}

The antioxidant activity of LDS and LDS-Zn was compared (Fig. 8). LDS had strong effect of scavenging DPPH free radicals with a linear relationship. LDS-Zn had better antioxidant activity than LDS. The IC50 of LDS was $0.81 \mathrm{mg} / \mathrm{mL}$. The IC50 of LDS-Zn was $0.62 \mathrm{mg} / \mathrm{mL}$. The antioxidant activity increased by $23.46 \%$. 


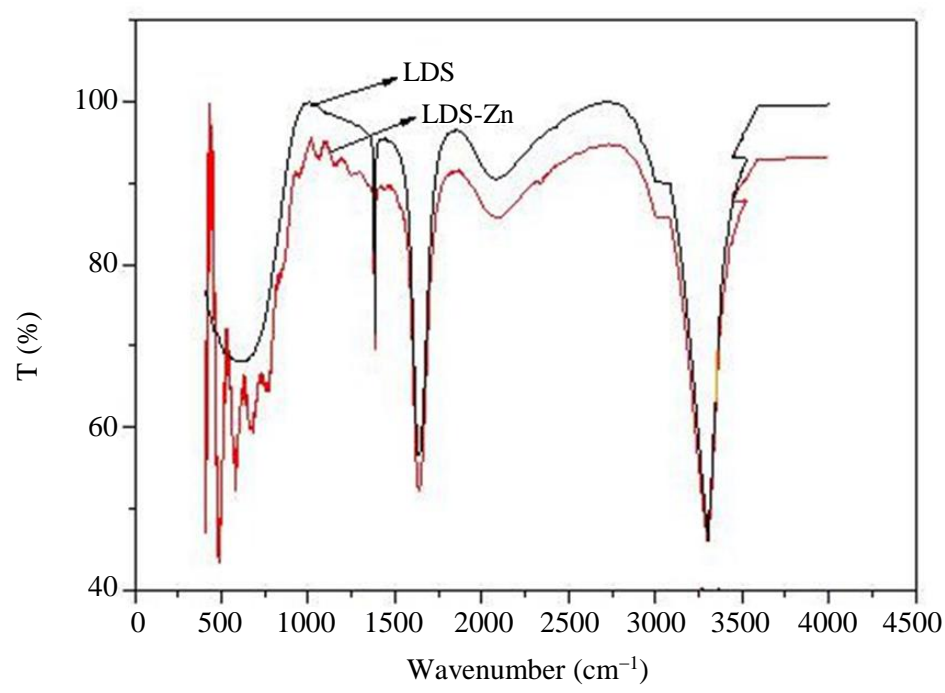

Fig. 7: Infrared spectroscopy of LDS and LDS-Zn

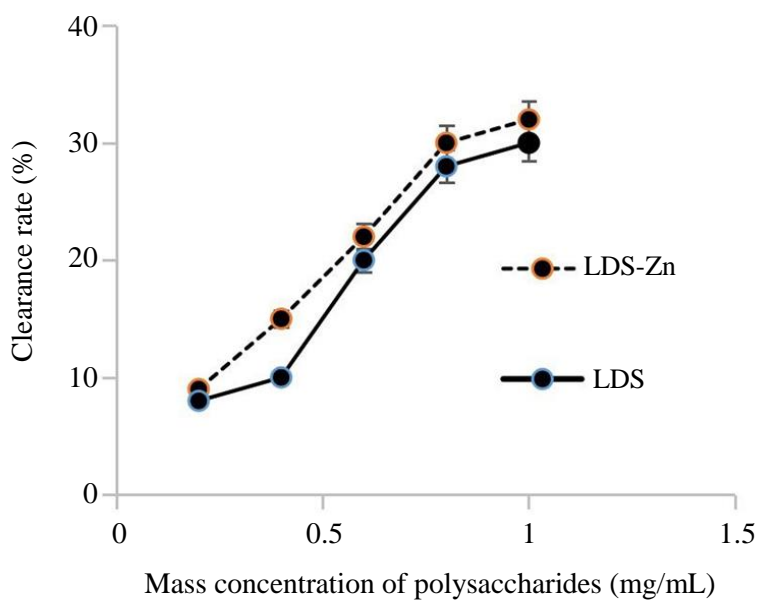

Fig. 8: Scavenging Effect of LDS and LDS-Zn on DPPH Free Radicals

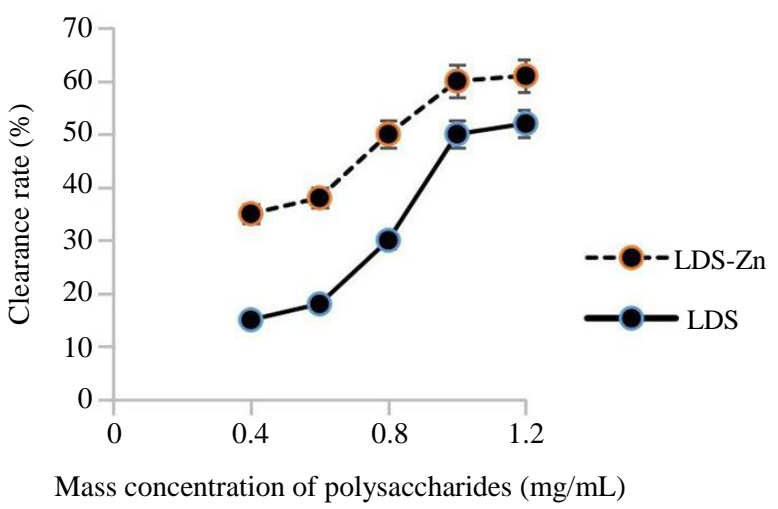

Fig. 9: Scavenging Effect of LDS and LDS-Zn on Hydroxyl Radicals

\section{Scavenging Effect of LDS and LDS-Zn on Hydroxyl Radicals}

Figure 9 indicated that LDS-Zn had a significantly higher clearance rate for hydroxyl radicals than LDS. The IC50 of LDS was $0.83 \mathrm{mg} / \mathrm{mL}$. The IC50 of LDS$\mathrm{Zn}$ was $0.75 \mathrm{mg} / \mathrm{mL}$. The antioxidant activity increased by $16.77 \%$.

\section{Conclusion}

According to the response surface method, the optimal preparation conditions of LDS-Zn were as obtained as follows: Chelating time was $4 \mathrm{~h}$, mass ratio (LDS with zinc) was 6:1, initial mass concentration (zinc) was $4 \mathrm{mg} / \mathrm{mL}$. LDS achieved the best chelating rate as high as $87.08 \%$. Infrared spectroscopy analysis showed that zinc (II) successfully chelated with LDS.

Compared with LDS, LDS-Zn had better scavenging effect on DPPH free radicals and hydroxyl radicals and antioxidant activity increased by 23.46 and $16.77 \%$, respectively. These results indicated that LDS-Zn could be expected to serve as a nutritional $\mathrm{Zn}$ supplement with antioxidant activity. Meanwhile, the results can provide some scientific basis for developing new $\mathrm{Zn}$ supplement. In future research, the mechanism of change in the antioxidant activity of LDS after chelating zinc as well as advantages of LDS-Zn as zinc supplement is not yet clear, which will be further studied.

\section{Acknowledgment}

The authors are grateful for the school-enterprise cooperation fund project (XJXZ2020394). 


\section{Author's Contributions}

Bing Xu: Participated in all experiments and article writing.

Yi Dai and Jing Hong: Participated in all experiments and data analysis.

Yiyong Chen: Participated in research plan and experimental guidance of this manuscript.

\section{Ethics}

This article is original and contains unpublished material. The corresponding author confirms that all of the other authors have read and approved the manuscript and no ethical issues involved.

\section{References}

Chen, Y. Y., \& Zhang, Y. (2016). Modification of carboxymethylation of Pleurotus eryngii polysaccharides and its antioxidant activity. Food and Fermentation Industry, 42(7), 119-127.(in Chinese).

Cheng, J. H. (2014). Current status and development prospects of commercial production of medicinal and medicinal fungus velvet mushroom. Edible bacterium, 22(4), 194-197. (in Chinese).

Cui, J. F., Du, C. Y., \& Chi, Y. Z. (2018). Optimization of preparation process and structural characterization of Brassica polysaccharide iron. Science and Technology of Food Industry, 39(5), 161-165.

Debon, S. J., \& Tester, R. F. (2001). In vitro binding of calcium, iron and zinc by non-starch polysaccharides. Food Chemistry, 73(4), 401-410.

Ding, C. M., Song, Q. P., \& Ye, S. M. (2003). Preparation of $\mathrm{Zn} \sim(2+)$-chitosan Chelate and Its IR and XPS Analysis. Journal of East China University of Science and Technology, 3, 315-316.

Dong, Y. F., Xu, T. Y., \& Yang, W. G. (2016). Optimization of preparation process of chelated zinc by enzymatic hydrolysate of fish with fish by response surface methodology. Journal of Nuclear Agricultural Sciences, 30(3), 541-547. (in Chinese).

Gu, B. F., Zhao, Y. Y., \& Chen, Y. Y. (2019). Preparation and Antioxidant Activity of Polysaccharide Zinc Chelate of Pleurotus eryngii. Food Research and Development, 40(4), 97-103. (in Chinese).

He, J. P., \& Lu, L. (2011). Study on chelation of trace element zinc by Flammulina velutipes polysaccharides. Science and Technology of Food Industry, 32(12), 301-303.(in Chinese).

Hedemann, M. S., Jensen, B. B., \& Poulsen, H. D. (2006). Influence of dietary zinc and copper on digestive enzyme activity and intestinal morphology in weaned pigs. Journal of animal science, 84(12), 3310-3320
Hu, L., Yue, G. W., \& Shi, Y. H. (2007). Study on Microwave Solid Phase Synthesis of Zinc Methionine. Food Additives, 28(1), 193-195. (in Chinese).

Jung, W. K., \& Kim, S. K. (2007). Calcium-binding peptide derived from pepsinolytic hydrolysates of hoki (Johnius belengerii) frame. European Food Research and Technology, 224(6), 763-767.

Li, C., Huang, Q., Xiao, J., Fu, X., You, L., \& Liu, R. H. (2016). Preparation of Prunella vulgaris polysaccharide-zinc complex and its antiproliferative activity in HepG2 cells. International journal of biological macromolecules, 91, 671-679.

Li, G. B., \& Wang, Z. Y. (2006). Preparation and infrared spectroscopy of polysaccharides from Auricularia auricula and $\mathrm{Fe}$ (II). Science and Technology of Food Industry, 5, 136-138. (in Chinese).

Liao, W., Lu, Y., Fu, J., Ning, Z., Yang, J., \& Ren, J. (2015). Preparation and characterization of dictyophora indusiata polysaccharide-zinc complex and its augmented antiproliferative activity on human cancer cells. Journal of agricultural and food chemistry, 63(29), 6525-6534.

Namkung, H., Gong, J., Yu, H., \& De Lange, C. F. M. (2006). Effect of pharmacological intakes of zinc and copper on growth performance, circulating cytokines and gut microbiota of newly weaned piglets challenged with coliform lipopolysaccharides. Canadian journal of animal science, 86(4), 511-522.

Qin, W. D., Ma, L. H., \& Zhuang, P. (2009). Preparation of chelating ferrous iron from Flammulina velutipes polysaccharides. Journal of Xuzhou Institute of Technology (Natural Science Edition), 24(4), 15-18. (in Chinese).

Raikwar, M. M., Avhad, K. C., Varghese, M., Mathew, E., Joe, I. H., \& Sekar, N. (2019). D- $\pi$ A- $\pi$-D coumarin hybrids derived from arylamine donors: DFT and Z-scan studies. Optical Materials, 92, 100-110.

Shang, Q. (2014). Scented pine mushroom taste velvet mushroom-Shanghai Fumao company 30,000 kg of velvet mushroom put on the market. Shanghai Enterprises, 1, 82. (in Chinese).

Wang, P. P., Huang, Q., Chen, C., You, L. J., Liu, R. H., Luo, Z. G., ... \& Fu, X. (2019). The chemical structure and biological activities of a novel polysaccharide obtained from Fructus Mori and its zinc derivative. Journal of Functional Foods, 54, 64-73.

Wang, X. R. (2008). Preparation technology and properties of pig blood peptide iron chelate salt. $\mathrm{PhD}$ thesis, Southwest University, Chongqing. (in Chinese).

Wu, M. Y., Wang, X. Z., \& Yu, T. N. (2014). Optimization of microwave extraction of polysaccharides from Hericium erinaceus by BoxBehnken effect surface method. Food Research and Development, 9, 23-26. (in Chinese). 
Yang, L., Yang, H. P., \& Qian, Q. (2004). Determination of Chelation Rate of Methionine with Iron, Copper, Manganese and Zinc Chelates. Food and Feed Industry, 4, 47-48. (in Chinese).

Yang, Y. L., Yang, Z. J., \& Tang, Q. S. (2017a). Study on Ganoderma Lucidum polysaccharide and trace element selenium chelate. Processing of Agricultural Products, 9, 1-3.(in Chinese).

Yang, S., Li, Y., Jia, D., Yao, K., \& Liu, W. (2017b). The synergy of Box-Behnken designs on the optimization of polysaccharide extraction from mulberry leaves. Industrial Crops and Products, 99, 70-78.
Zhang, M., Zhao, H., Shen, Y., Wang, Y., Zhao, Z., \& Zhang, Y. (2020). Preparation, characterization and antioxidant activity evaluation in vitro of Fritillaria ussuriensis polysaccharide-zinc complex. International Journal of Biological Macromolecules, 146, 462-474.

Zhao, S. W., Xia, Y., \& Chen, G. T. (2016). Inhibition of Proliferation and Antioxidant Activity of Flammulina velutipes Polysaccharide- $\mathrm{Zn}^{2+}$ Chelate on L929 Tumor Cells. Food Science, 37(5), 202-207. (in Chinese). 